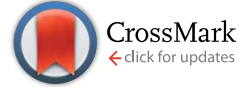

Cite this: J. Mater. Chem. A, 2016, 4, 8762

Received 26th March 2016 Accepted 3rd May 2016

DOI: 10.1039/c6ta02548j

www.rsc.org/MaterialsA

\section{Dandelion-shaped $\mathrm{TiO}_{2} /$ multi-layer graphene composed of $\mathrm{TiO}_{2}$ (B) fibrils and anatase $\mathrm{TiO}_{2}$ pappi utilizing triphase boundaries for lithium storage $\uparrow$}

\begin{abstract}
Weixin Song, ${ }^{a}$ Jun Chen, ${ }^{b}$ Xiaobo Ji, ${ }^{b}$ Xuemei Zhang, ${ }^{a}$ Fang Xie ${ }^{a}$ and D. Jason Riley ${ }^{\star a}$
A three-dimensional dandelion-shaped $\mathrm{TiO}_{2} /$ multi-layer graphene compound $\left(\mathrm{TiO}_{2} / \mathrm{MLG}\right)$ composed of $\mathrm{TiO}_{2}$ (B) fibrils and anatase pappus structures has been synthesized as a potential anode material for $\mathrm{Li}$ storage. Electron microscopy indicates that the composite contains triphase boundaries between anatase, $\mathrm{TiO}_{2}(\mathrm{~B})$ and graphene, which are responsible for the enhancement of energy storage and the decrease of electrode polarization. Cyclic voltammetric investigations indicate that both $\mathrm{Li}^{+}$insertion and pseudocapacitance contribute to charge storage. Ultrahigh specific capacities of 243 and $182 \mathrm{~mA} \mathrm{~h} \mathrm{~g}^{-1}$ have been obtained at 0.1 and $1 \mathrm{~A} \mathrm{~g}^{-1}$, respectively. Moreover, the excellent capacity retention can reach $99.6 \%$ after 100 cycles with almost $100 \%$ coulombic efficiency at $0.1 \mathrm{~A} \mathrm{~g}^{-1}$. The importance of the triphase boundary in enhancing the storage of charge and transport of $\mathrm{Li}^{+}$is demonstrated.
\end{abstract}

\section{Introduction}

As a consequence of an increasing demand for energy, improved energy storage is required to enable future power systems. Lithium-ion batteries offer high energy and power density and as a result are attracting great interest with a focus on designing electrodes that can enhance energy-storage performance. ${ }^{1,2}$ Titanium dioxide $\left(\mathrm{TiO}_{2}\right)$, one of the most promising anode materials, has been intensively studied, not only due to its low cost, abundance and non-toxicity but also on account of the negligible volume deformation during the Li-ion insertion/de-insertion processes (intercalation is preferred to describe lithium storage in a laminar host structure $)^{3}$ and excellent gravimetric capacity. ${ }^{3-5}$ The operational potential of $\mathrm{TiO}_{2}$ is high $\left(>1 \mathrm{~V} v s . \mathrm{Li}^{+} / \mathrm{Li}\right)$, which can enhance battery safety by reducing the probability of the formation of lithium dendrites at the anode surface and avoiding the formation of a solid electrolyte interface (SEI) ${ }^{6-8}$ To-date various polymorphs of $\mathrm{TiO}_{2}$ including anatase (tetragonal), ${ }^{9}$ rutile (tetragonal), ${ }^{5}$ brookite (orthorhombic ${ }^{10}$ and bronze $\left(\mathrm{TiO}_{2}-\mathrm{B} \text {, monoclinic) }\right)^{11}$ have been extensively studied as anode materials in lithium-ion batteries. The other allotropes, which either are easily transformed to other types like ramsdellite $\left(\mathrm{TiO}_{2}-\mathrm{R}\right)^{12}$ and hollandite $\left(\mathrm{TiO}_{2}-\mathrm{H}\right)^{13}$ or need high-pressure and high-temperature synthesis conditions, such as $\alpha-\mathrm{PbO}_{2}$-structured $\mathrm{TiO}_{2}(\mathrm{II}){ }^{14}$ baddeleyite, ${ }^{15}$

\footnotetext{
${ }^{a}$ Department of Materials, Imperial College London, London SW72AZ, UK. E-mail: jason.riley@imperial.ac.uk

${ }^{b}$ College of Chemistry and Chemical Engineering, Central South University, Changsha 410083, China
}

$\dagger$ Electronic supplementary information (ESI) available. See DOI: $10.1039 / \mathrm{c} 6 \mathrm{ta} 02548 \mathrm{j}$ columbite ${ }^{16}$ cubic, ${ }^{17} \mathrm{TiO}_{2}(\mathrm{OI})^{18}$ and $\mathrm{TiO}_{2}(\mathrm{OII}),{ }^{19}$ have been rarely researched. Despite the numerous studies, $\mathrm{TiO}_{2}$ has not been used extensively as a high rate anode material owing to its limited ability to store charge and poor conductivity.

An intrinsic drawback of $\mathrm{TiO}_{2}$ is the material's poor electronic conductivity $\left(10^{-13} \mathrm{~S} \mathrm{~cm}^{-1}\right)^{5,20,21}$ and limited ionic conductivity. ${ }^{22}$ Several solutions have been proposed to overcome this issue including: (i) addition of a conducting phase, e.g., carbon coating $^{23}$ or compositing with transition metal oxides, ${ }^{24}$ (ii) reduction of the ionic diffusion length by fabricating nanoscale $\mathrm{TiO}_{2}$ structures such as wires, ${ }^{25}$ tubes, ${ }^{26}$ cubes, ${ }^{27}$ rods ${ }^{28}$ and flowers, ${ }^{8}$ and (iii) doping through either the introduction of $\mathrm{Ti}^{3+}$ or oxygen vacancies ${ }^{5,29}$ or with heteroatoms $\mathrm{B},{ }^{30} \mathrm{C},{ }^{6} \mathrm{~N},{ }^{31} \mathrm{~S},{ }^{32} \mathrm{Ni}^{33} \mathrm{Zn}^{34}$ or $\mathrm{Sn}^{35}$ Charge stored in $\mathrm{Li}^{+} /$heterophase anode system may be enhanced ${ }^{36-39}$ through interfacial charge storage at both the solidliquid interface and internal solid-solid interfaces. Jamnik and Maier have demonstrated increased charge storage at $\mathrm{TiO}_{2}-$ metal interfaces as a result of the metal acting as an electron sink and the $\mathrm{TiO}_{2}$ storing excess $\mathrm{Li}^{+}$. In $\mathrm{TiO}_{2}$ photochemical studies, it has been demonstrated that owing to the offset in the conduction band levels, photogenerated charge carriers can be stored at the junction between anatase and $\mathrm{TiO}_{2}(\mathrm{~B}){ }^{40-42}$ This band offset has been employed in $\mathrm{TiO}_{2}$ engineering to yield a material in which $\mathrm{Li}^{+}$and electrons are separated across $\mathrm{TiO}_{2}(\mathrm{~B}) /$ anatase $\mathrm{TiO}_{2}$ interfaces within the anode leading to increased charge storage.

In the present work we have fabricated a new $\mathrm{TiO}_{2}$-graphene composite designed to enhance the prospects of this low cost, abundant, non-toxic material as an anode in a Li-battery. The $\mathrm{TiO}_{2}$ is dandelion shaped with nanosized $\mathrm{TiO}_{2}$ (B) fibrils capped with anatase $\mathrm{TiO}_{2}$ pappi. The as-prepared structure has extensive solid-electrolyte and solid-solid junctions to maximize interfacial charge storage. Multilayered graphene (MLG) is 
added to the $\mathrm{TiO}_{2}$ phases to yield a composite with enhanced conductivity and an increased number of solid-solid junctions.

\section{Experimental}

Materials preparation: dandelion-shaped $\mathrm{TiO}_{2} /$ multi-layer graphene $\left(\mathrm{TiO}_{2} / \mathrm{MLG}\right)$ and the compared $\mathrm{TiO}_{2}$ anode materials were synthesized by a solvent-thermal method. For $\mathrm{TiO}_{2} / \mathrm{MLG}$ preparation, $0.24 \mathrm{~g}$ polyvinylpyrrolidone (PVP, Sigma, average mole weight: 360000 ) was dissolved in $40 \mathrm{~mL}$ acetic acid solution (Sinopharm Chemical Reagent Beijing Co. Ltd.) by strong stirring, followed by the addition of $0.05 \mathrm{~g}$ multi-layer graphene ( $\sim 10 \mathrm{~nm}$ thickness, Hefei Weijing Material Technology Co. Ltd.) and continuous stirring for $20 \mathrm{~min}$. Then, $1 \mathrm{~mL}$ tetrabutyl titanate (TBT, Sinopharm Chemical Reagent Beijing Co. Ltd.) was added dropwise to the above dark solution in $5 \mathrm{~min}$, and the mixture was sealed to sonicate at a power of $99 \mathrm{~W}$ for $20 \mathrm{~min}$ at $50{ }^{\circ} \mathrm{C}$. The obtained suspension was transferred to a $60 \mathrm{~mL}$ Teflon-lined stainless-steel autoclave, and maintained at $150{ }^{\circ} \mathrm{C}$ for $24 \mathrm{~h}$. After being cooled to room temperature, the precipitate was collected by centrifuge, washed with ethanol and water several times and dried at $60{ }^{\circ} \mathrm{C}$ in an oven. The dried sample was then calcined in the tube furnace at $400{ }^{\circ} \mathrm{C}$ for $4 \mathrm{~h}$ flowing with an argon atmosphere, and the temperature rose from room temperature with an increase rate of $3^{\circ} \mathrm{min}^{-1}$. After grinding, the $\mathrm{TiO}_{2} / \mathrm{MLG}$ powder was obtained. The compared $\mathrm{TiO}_{2}$ sample was prepared using the same method but without the use of multi-layer graphene.

Characterization: the crystallographic structure of the asprepared materials was studied by X-ray powder diffraction (XRD) using a Bruker D8 diffractometer with monochromatic $\mathrm{Cu} \mathrm{K} \alpha$ radiation $(\lambda=1.5406 \AA)$, and the diffraction data were recorded in the $2 \theta$ range of $10-80^{\circ}$. The morphological structures of the anode materials were investigated by a FEI Quanta 200 scanning electron microscopy (SEM) and JEOL 2010F transmission electron microscopy (TEM). The thermogravimetric analysis/differential scanning calorimetry (TGA/DSC) of the samples was carried out on a Diamond TG thermoanalyzer.

Electrochemical tests: the anode was fabricated with the active material, acetylene black, and binder (polyvinylidene fluoride, PVDF) in a weight ratio of $8: 1: 1$ by using NMP as the solvent and copper foil as the current collector $(\sim 2.5 \mathrm{mg}$ $\mathrm{cm}^{-2}$ ), followed by drying in vacuum at $110{ }^{\circ} \mathrm{C}$ for $24 \mathrm{~h}$. The R2016 coin cell was assembled in an argon-filled glove box using metallic lithium as the cathode and Celgard 2500 membrane as the separator. The electrolyte was $1 \mathrm{M} \mathrm{LiPF}_{6}$ dissolved in a mixture of ethylene carbonate (EC), dimethyl carbonate (DMC), diethyl carbonate (DEC) (v/v/v, 1/1/1). Cyclic voltammetry (CV) and galvanostatic charge/discharge cycling tests were carried out in a setting voltage range by using an electrochemical workstation (CHI660C) and a CT2001A LAND battery tester, respectively. Electrochemical impedance spectroscopy (EIS) was studied using a Modulab (Solartron Analytical) with the amplitude of $5 \mathrm{mV}$ in the frequency range from $1 \mathrm{MHz}$ to $10 \mathrm{mHz}$. All electrochemical tests were carried out at room temperature.

\section{Results and discussion}

The X-ray diffraction (XRD) pattern of the as-prepared composite is shown in Fig. 1. The diffraction pattern can be indexed to the three constituent phases of the composite, namely graphite $\left(\mathrm{P6}_{3} / \mathrm{mmc}\right.$, JPCD no. 65-6212), anatase $\mathrm{TiO}_{2}$ (I4/ /amd, JPCD no. 65-5714) and $\mathrm{TiO}_{2}(\mathrm{~B})(C 2 / m$, JPCD no. 46-1238). The observed graphite peak is evidence of the incorporation of the multi-layer graphene (MLG) which was used as a reagent during the preparation. The strong (002) diffraction peak at $26.5^{\circ}$ illustrates that the MLG structure was maintained throughout the hydrothermal and calcination processes employed in fabrication. ${ }^{\mathbf{4 3 , 4 4}} \mathrm{TiO}_{2}(\mathrm{~B})$ is formed from the thermal dehydration of layered hydrogen titanate, ${ }^{45,46}$ resulting from the low-rate of hydrolysis of TBT in acetic acid. The slow hydrolysis of the TBT precursor with the help of the PVP dispersant is beneficial for the self-assembly of anatase and $\mathrm{TiO}_{2}(\mathrm{~B})$. Rietveld refinement of the diffraction pattern using a two-phase analysis model, see Fig. $\mathrm{S} 1, \uparrow$ indicates that the phase content of anatase $\mathrm{TiO}_{2}$ and $\mathrm{TiO}_{2}$ (B) are $70.7 \%$ and $29.3 \%$, respectively.

In order to estimate the amount of MLG in the composite sample, thermal analysis/differential scanning calorimetry (TGA/DSC) was carried out in air with a heating speed of $5{ }^{\circ} \mathrm{C}$ $\min ^{-1}$ (Fig. S2 $\dagger$ ). The slight weight loss before $120^{\circ} \mathrm{C}$ is ascribed to the evaporation of adsorbed water molecules. As the complete decomposition temperature of graphene has been generally considered to be around $700{ }^{\circ} \mathrm{C},{ }^{47-50}$ the weight loss at this temperature has been assumed to correspond to the content of MLG in the $\mathrm{TiO}_{2} / \mathrm{MLG}$ composite, which is estimated to be $5.8 \%$. In addition, the wide exothermic peaks of $\mathrm{TiO}_{2} / \mathrm{MLG}$ reflects the oxidization of the carbon skeleton of MLG, which can be affected by the formed $\mathrm{C}-\mathrm{Ti}$ bond and the distribution of $\mathrm{TiO}_{2}$ creating localized spots to facilitate the oxidization reaction. ${ }^{51-53}$ Besides MLG, the phase transformation of $\mathrm{TiO}_{2}$ from $\mathrm{TiO}_{2}$ (B) to anatase to rutile in the range of $350-600{ }^{\circ} \mathrm{C}$ causes fluctuations in the exothermic peaks. ${ }^{54,55}$

The dandelion-shaped $\mathrm{TiO}_{2} / \mathrm{MLG}$ with $\mathrm{TiO}_{2}(\mathrm{~B})$ fibrils and anatase $\mathrm{TiO}_{2}$ pappi was characterized by scanning electron microscopy (SEM) and transmission electron microscopy

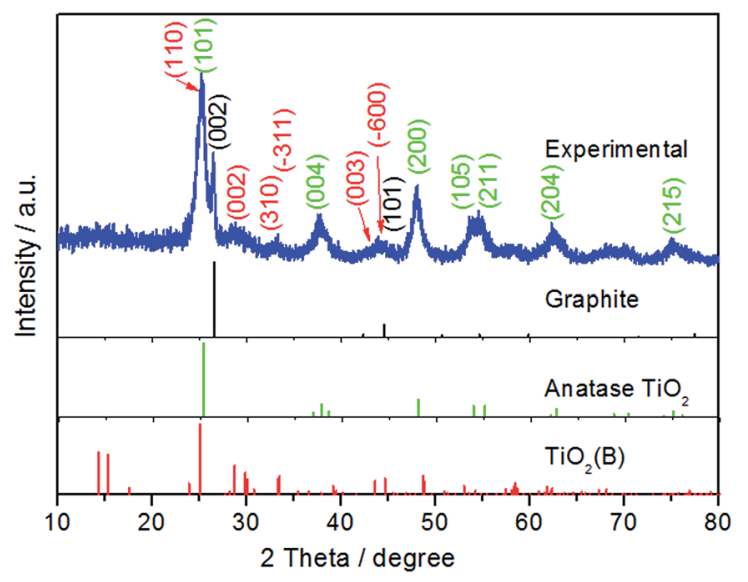

Fig. 1 XRD patterns of the as-prepared sample. 


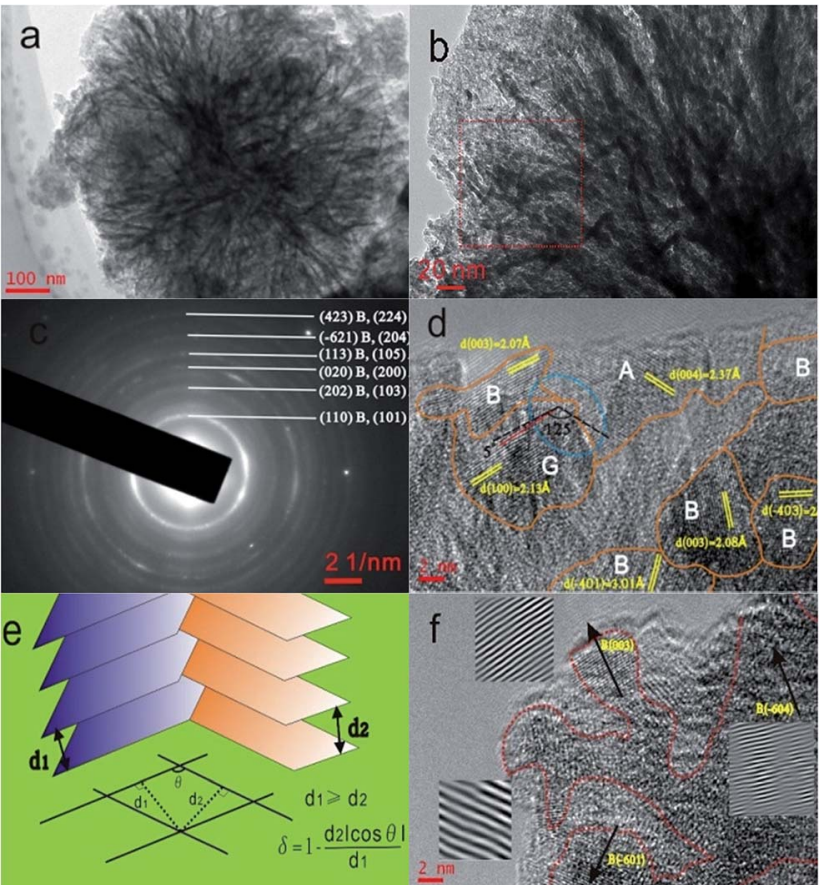

Fig. 2 (a) TEM image of $\mathrm{TiO}_{2} / \mathrm{MLG}$ morphology. (b) Magnified TEM image around the outer region of $\mathrm{TiO}_{2} / \mathrm{MLG}$. (c) Corresponding SAED pattern of the rectangular area in (b). $\mathrm{A}$ and $\mathrm{B}$ represent anatase $\mathrm{TiO}_{2}$ and $\mathrm{TiO}_{2}(\mathrm{~B})$, respectively. (d) HRTEM image with interface lines between phase regions. $\mathrm{A}, \mathrm{B}$ and $\mathrm{G}$ in the image indicate anatase $\mathrm{TiO}_{2}$, $\mathrm{TiO}_{2}(\mathrm{~B})$ and graphene phase, respectively. (e) Representation of the interface mismatch rate, $\delta$, between two adjacent phases. (f) HRTEM image of the focused limb part with the magnified lattice plane by FFT and inverse FFT.

(TEM). Fig. 2(a) and (b) show that $\mathrm{TiO}_{2} / \mathrm{MLG}$ is composed of connected ultrathin nanowires and nanosheets, with a thickness of several nanometers. The SEM image of $\mathrm{TiO}_{2} / \mathrm{MLG}$ is shown in Fig. S3† with the spherical dandelion morphology. The selected area electron diffraction (SAED) pattern shown in Fig. 2c displays broad diffraction rings that can be assigned to a composite of the two $\mathrm{TiO}_{2}$ polymorphs, namely anatase $\mathrm{TiO}_{2}$ and $\mathrm{TiO}_{2}(\mathrm{~B})$, and the broad rings assigned to (110), (202), (020), (113), (-621) and (423) planes for $\mathrm{TiO}_{2}(\mathrm{~B})$ can also be identified to the (101), (103), (200), (105), (204) and (224) planes of anatase $\mathrm{TiO}_{2}{ }^{4}$ The high resolution transmission electron microscopy (HRTEM) image of $\mathrm{TiO}_{2} / \mathrm{MLG}$ displayed in Fig. 2d clearly demonstrates the crystal domains of the three phases in a nanoregion, and the boundary structures between anatase $\mathrm{TiO}_{2}$ and $\mathrm{TiO}_{2}(\mathrm{~B})$. Within the triple phase region indicated by an ellipse in Fig. 2d, it is found that the lattice fringes of the (003) plane of $\mathrm{TiO}_{2}(\mathrm{~B})$ and the (004) plane of anatase $\mathrm{TiO}_{2}$ are adjacent with a $125^{\circ}$ angular mismatch, and there is a $5^{\circ}$ angular mismatch between the (100) plane of graphene and the (003) plane of $\mathrm{TiO}_{2}(\mathrm{~B})$ and $120^{\circ}$ between the (100) plane of graphene and the (004) plane of anatase $\mathrm{TiO}_{2}$. As depicted in Fig. 2e, the interface mismatch rate, $\delta$, between two mismatched phases can be calculated using eqn (1) where $\delta$ reflects the interface matching intensity or the possibility of interface match. ${ }^{4}$

$$
\delta=1-\frac{d_{2}|\cos \theta|}{d_{1}} \quad d_{1} \geq d_{2}
$$

The schematically presented parameters $d_{1}$ and $d_{2}$ signify the projected lengths of mismatched planes and eqn (1) may be employed when $d_{1} \geq d_{2}$. $\delta$ is calculated to be $0.497,0.032$ and 0.539 for the interfaces between the (003) plane of $\mathrm{TiO}_{2}(\mathrm{~B})$ and the (004) plane of anatase, the (003) plane of $\mathrm{TiO}_{2}(\mathrm{~B})$ and (100) plane of graphene, the (004) plane of anatase and (100) plane of graphene, respectively. More abundant interfacial structure is present between graphene and anatase in this triphase composite than between anatase and $\mathrm{TiO}_{2}(\mathrm{~B})$. By employing Fast Fourier Transform (FFT) and inverse FFT, the magnified lattices of the corresponding darker parts in the HRTEM image displayed in Fig. $2 \mathrm{f}$ are assigned to $\mathrm{TiO}_{2}(\mathrm{~B})$, which demonstrates that the crystals of this phase form the fibrils whilst the lighter pappus parts are composed of anatase $\mathrm{TiO}_{2}$ and the complementary analysis is shown in Fig. S4. $\dagger$ In addition, it is clearly observed from the FFT images in Fig. $2 f$ that the lattice plane of $(-604)$ displays a degree of disorder.

Cyclic Voltammetry (CV) of $\mathrm{TiO}_{2} / \mathrm{MLG}$ was performed in a voltage range of $1-3 \mathrm{~V} v s . \mathrm{Li} / \mathrm{Li}^{+}$, and the $\mathrm{CV}$ curves are shown in Fig. $3 \mathrm{a}$ and $\mathrm{b}$. The first $\mathrm{CV}$ cycle, beginning from the open circuit voltage, shows different electrochemical behavior to the subsequent cycles, consistent with conditioning of the anode material during the first round of $\mathrm{Li}$ insertion/de-insertion. The second and fourth cycles are consistent in shape illustrating excellent reversibility of the reactions for the as-prepared material. ${ }^{4,7}$ The cathodic peak located at $1.37 \mathrm{~V} v$ s. $\mathrm{Li} / \mathrm{Li}^{+}$in the first cycle is found to disappear in the following, which has been explained as the irreversible reactions of some impurities. ${ }^{4}$ Compared with the $\mathrm{CV}$ peaks of $\mathrm{TiO}_{2}(\mathrm{~B}),{ }^{7}$ the cathodic peak at around $1.4 \mathrm{~V}$ in the first cycle results from the open channel saturation of $\mathrm{TiO}_{2}(\mathrm{~B})$ by the inserted $\mathrm{Li}^{+}$ions. In the anodic scan of the second cycle there are three distinct peaks labeled A, B1 and B2 in Fig. 3a. At higher scan rates, Fig. 3b, peaks B1 and B2 are less well defined and eventually merge into a single entity labeled B. Analysis of peaks A and B as the scan rate is varied from $0.2 \mathrm{mV} \mathrm{s}^{-1}$ to $1.2 \mathrm{mV} \mathrm{s}^{-1}$ indicates that the peak current of the former is a linear function of the square root of the scan rate, Fig. 3(c), whilst the height of the latter is directly proportional to the scan rate, Fig. 3d. The as-prepared $\mathrm{TiO}_{2} / \mathrm{MLG}$ includes a mixture of anatase and $\mathrm{TiO}_{2}(\mathrm{~B})$ presenting diffusionand surface-controlled electrochemical reactions at different potentials. ${ }^{3,4,7}$ The position of peak $\mathrm{A}, 1.68 \mathrm{~V} v$ s. $\mathrm{Li} / \mathrm{Li}^{+}$, and the variation in peak height with scan rate are consistent with lithium insertion into anatase $\mathrm{TiO}_{2} .{ }^{5}$ Peak $\mathrm{B}$ can be assigned to a pseudocapacitive process on the surface of $\mathrm{TiO}_{2}(\mathrm{~B}) \cdot{ }^{56} \mathrm{~A}$ higher current associated with anatase $\mathrm{TiO}_{2}$ is in agreement with the composition of the composite.

The galvanostatic charge/discharge profiles in the voltage range of 1 to $3 \mathrm{~V} v s$. $\mathrm{Li} / \mathrm{Li}^{+}$of $\mathrm{TiO}_{2} / \mathrm{MLG}$ and $\mathrm{TiO}_{2}$ prepared using the same synthetic method but without MLG are shown in Fig. 4a. The discharge curves of $\mathrm{TiO}_{2} / \mathrm{MLG}$ and $\mathrm{TiO}_{2}$ can be divided into three regions. ${ }^{36,57}$ The first region (Region 1) with a steep decrease in potential is ascribed to the homogeneous $\mathrm{Li}^{+}$ insertion into bulk $\mathrm{TiO}_{2}$ until the solid-solution limit of $\mathrm{Li}^{+}$ions 

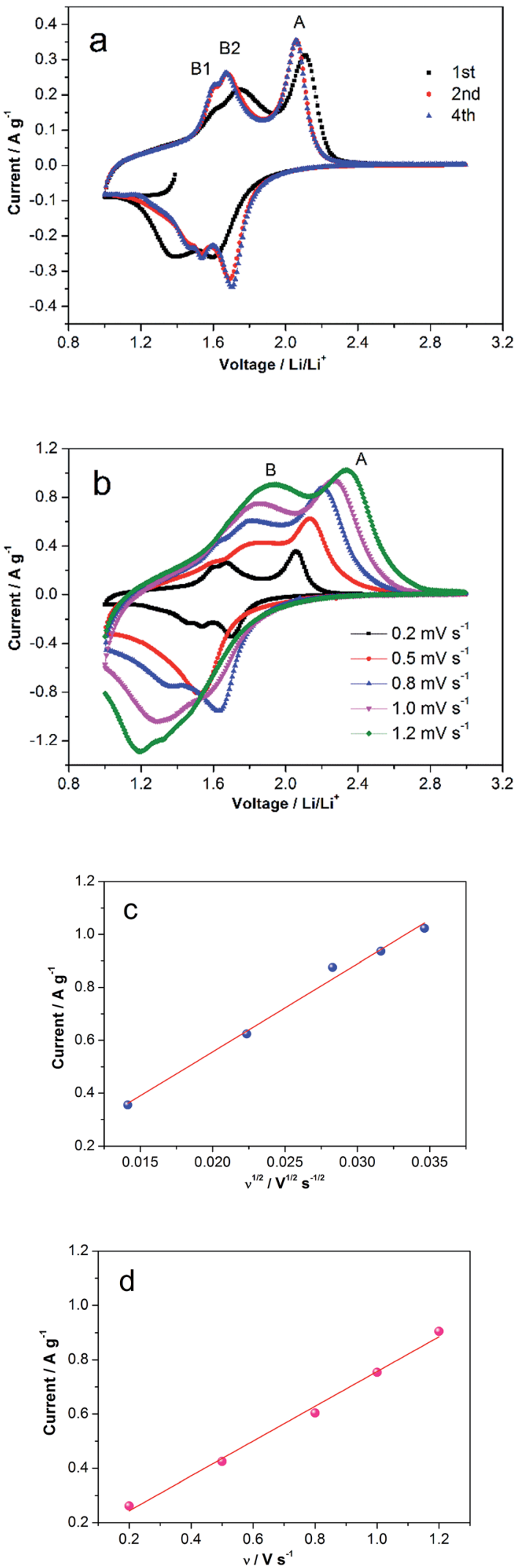

Fig. $3 \mathrm{CV}$ curves of $\mathrm{TiO}_{2} / \mathrm{MLG}$. (a) The first four cycles at the scan rate of $0.2 \mathrm{mV} \mathrm{s}^{-1}$. (b) CV curves at different scan rates from 0.2 to $1.2 \mathrm{mV}$ $\mathrm{s}^{-1}$. Linear relationships of (c) the A peak currents $v s$. square root of scan rates, and (d) the $S$ peak currents $v s$. scan rates from (b).
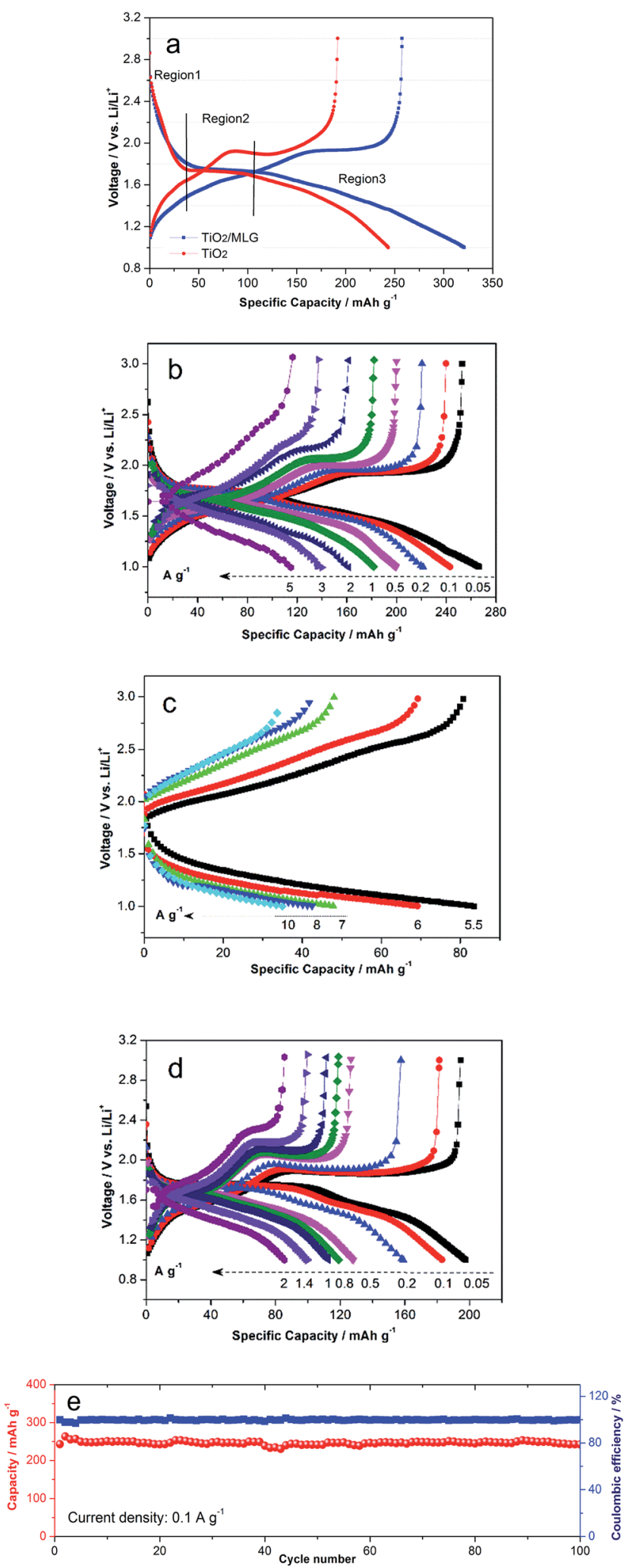

Fig. 4 Galvanostatic charge/discharge profiles. (a) The first cycle of $\mathrm{TiO}_{2} / \mathrm{MLG}$ and $\mathrm{TiO}_{2}$ at a current density of $0.05 \mathrm{~A} \mathrm{~g}^{-1}$. (b) Rate performances of $\mathrm{TiO}_{2} / \mathrm{MLG}$ from 0.05 to $2 \mathrm{~A} \mathrm{~g}^{-1}$ and (c) from 5.5 to 10 $\mathrm{A} \mathrm{g}^{-1}$. (d) Rate performances of $\mathrm{TiO}_{2}$ from 0.05 to $2 \mathrm{~A} \mathrm{~g}^{-1}$. (e) Cycling performances of $\mathrm{TiO}_{2} / \mathrm{MLG}$ at $0.1 \mathrm{~A} \mathrm{~g}^{-1}$. 
in $\mathrm{TiO}_{2}$, such behavior is indicative of a nano-sized titania material. ${ }^{58}$ Region 2 is characteristic of the lithiation of anatase. It can be seen that the average voltage plateau of $\mathrm{TiO}_{2} / \mathrm{MLG}$ $(1.75 \mathrm{~V})$ is $20 \mathrm{mV}$ higher than that of $\mathrm{TiO}_{2}(1.73 \mathrm{~V})$, from which it can be deduced that the boundary structures between $\mathrm{TiO}_{2}$ and graphene have the potential to lower the electrode polarization resulting from the good electronic and ionic conductivity ${ }^{\mathbf{4 4}}$ in the biphase $\mathrm{TiO}_{2}$ (Li-rich and $\mathrm{Li}$-poor) co-existence plateau. ${ }^{36}$ The contributed capacities of 126 and $106 \mathrm{~mA} \mathrm{~h} \mathrm{~g}^{-1}$ for $\mathrm{TiO}_{2} /$ MLG and $\mathrm{TiO}_{2}$ in the two regions result from the random insertion of $\mathrm{Li}^{+}$into over half the available interstitial octahedral sites of anatase. ${ }^{4,57}$ Region 3, at low potentials, corresponds to the loss of pseudocapacitive charges from the interfaces in the system. The $\mathrm{TiO}_{2} / \mathrm{MLG}$ composite anode and the $\mathrm{TiO}_{2}$ anode have very similar behavior in regions 1 and 2 of the discharge curve indicating that the degree of lithiation of the nanoparticles is independent of the amount of MLG. In region 3 the $\mathrm{TiO}_{2} / \mathrm{MLG}$ composite displays a higher specific capacity at all potentials. In the second and third cycles, region 3 of the $\mathrm{TiO}_{2} /$ MLG composite can be divided into two slopes of different gradients whilst for the $\mathrm{TiO}_{2}$ anode a single gradient is observed, as shown in Fig. S5. $\uparrow$ The columbic efficiency of $\mathrm{TiO}_{2} /$ MLG in the first cycle is $80.4 \%$, slightly higher than the $78.8 \%$ observed for the $\mathrm{TiO}_{2}$ anode.

Fig. $4 \mathrm{~b}$ shows the discharge capacities of $\mathrm{TiO}_{2} / \mathrm{MLG}$ at current densities of $0.05,0.1,0.2,0.5,1,2,3$ and $5 \mathrm{~A} \mathrm{~g}^{-1}$ to be 266, 243, 221, 200, 182, 161, 140 and $115 \mathrm{~mA} \mathrm{~h} \mathrm{~g}^{-1}$. For the higher discharge rates of $5.5,6,7,8$, and $10 \mathrm{~A} \mathrm{~g}^{-1}$ the capacities of $\mathrm{TiO}_{2} / \mathrm{MLG}$ are 84, 69, 48, 43 and $35 \mathrm{~mA} \mathrm{~h} \mathrm{~g}{ }^{-1}$, as indicated in Fig. 4c. For comparison, the specific discharge capacities of $\mathrm{TiO}_{2}$ displayed in Fig. 4d are 198, 183, 159, 128, 119, 113, 100 and $86 \mathrm{~mA} \mathrm{~h} \mathrm{~g}^{-1}$ for current densities of $0.05,0.1,0.2,0.5,0.8,1$, 1.4 and $2 \mathrm{Ag}^{-1}$, respectively. It is found that the specific capacity of $\mathrm{TiO}_{2} / \mathrm{MLG}$ at $1 \mathrm{~A} \mathrm{~g}^{-1}$ retains $75 \%$ of the value at $0.1 \mathrm{~A} \mathrm{~g}^{-1}$, while $\mathrm{TiO}_{2}$ keeps $62 \%$. The cyclic performances of $\mathrm{TiO}_{2} / \mathrm{MLG}$ in Fig. 4e was investigated to evaluate the electrode stability. Only a slight loss of capacity was observed after 100 cycles at a current density of $0.1 \mathrm{~A} \mathrm{~g}^{-1}$. The corresponding capacity retention of $\mathrm{TiO}_{2} /$ MLG is $99.6 \%$ with high coulombic efficiency almost approaching $100 \%$, even for high current rates of 5 and $10 \mathrm{Ag}^{-1}$ as illustrated in Fig. S6. $\uparrow$ The coulombic efficiencies of the 1200 cycles of $\mathrm{TiO}_{2} /$ MLG are extremely coincident when compared with that of the reference $\mathrm{TiO}_{2}$ (Fig. S7†), which confirms the high electrode stability of $\mathrm{TiO}_{2} / \mathrm{MLG}$ during cycling. With reference to the conclusions from Wu et al., ${ }^{4}$ the high electrochemical stability of the electrode is attributed to the threedimensional dandelion-shaped microsphere structure which provides short diffusion distance for ion transport, high contact area between the electrolyte and electrode and the boundaries of $\mathrm{TiO}_{2} / \mathrm{MLG}$ which are capable of accommodating strain during cycling, leading to high $\mathrm{Li}^{+}$diffusion kinetics as well as stable electrochemical reactions.

Electrochemical impedance spectroscopy (EIS) was used to explore the variation of impedance of $\mathrm{TiO}_{2} / \mathrm{MLG}$ during electrochemical cycling. Fig. 5(a) and (b) show the Nyquist plots for the electrodes cycled 0 and 1000 times with corresponding calculated plots which are obtained from the equivalent circuit
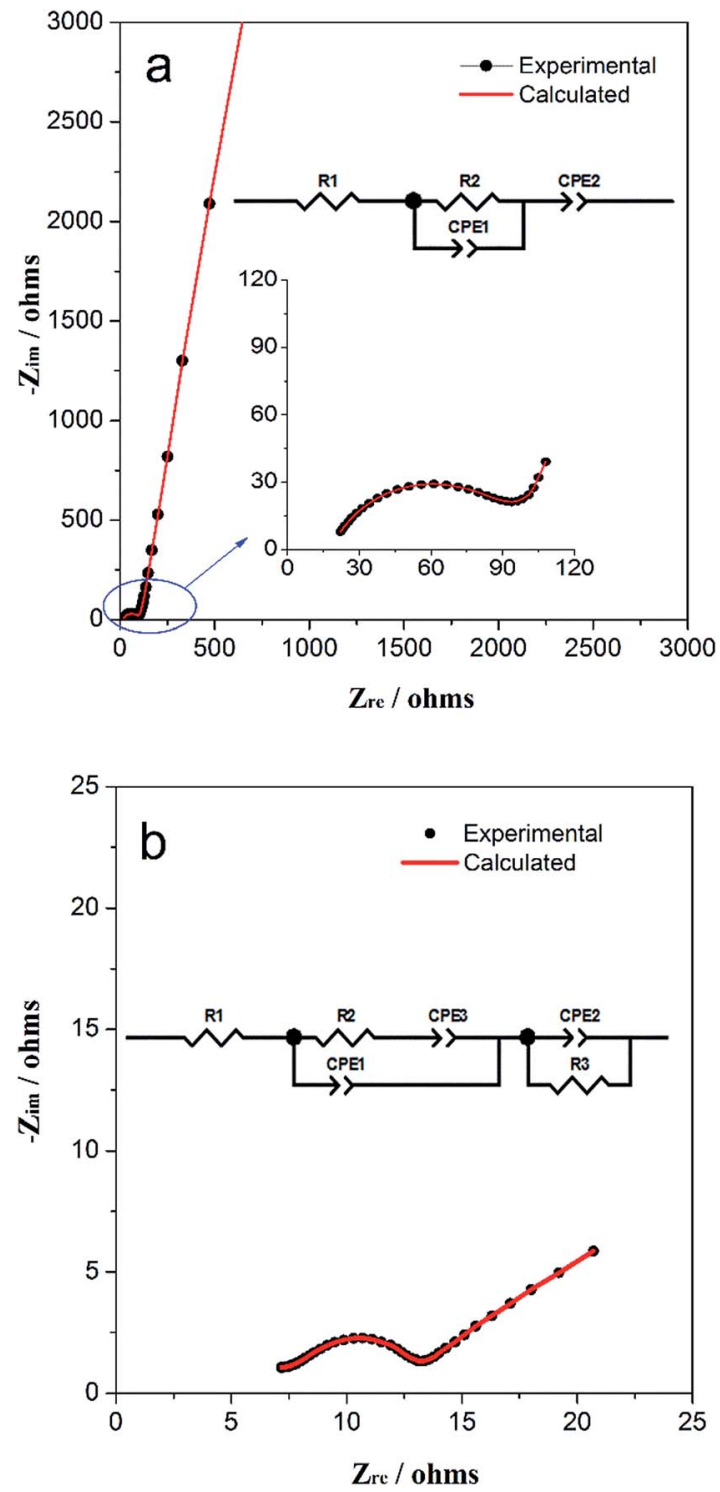

Fig. 5 Nyquist plot of the $\mathrm{TiO}_{2} /$ MLG cell after (a) 0 and (b) 1000 cycles with corresponding calculated fitting results. The inset is the corresponding equivalent circuit model.

model in the inset, respectively. For the components in the equivalent circuit, the values, with errors, that were calculated to yield the best fits to the experimental data are listed in Table $\mathrm{S} 1$ and $\mathrm{S} 2 . \dagger$ In the equivalent circuit of both, $R 1$ represents the internal resistance of the cell that arises from both the electrode and electrolyte. CPE2 (constant phase element) in Fig. 5a represents the pseudocapacitance that is generated on the complicated surface of internal triphase boundaries ${ }^{4}$ plus electrodes. $R 2$ represents the charge transfer and possible ion diffusion, and CPE1 is the capacitor in the bulk associated with $\mathrm{Li}^{+}$ion insertion. In Fig. 5b, two new components are introduced namely CPE3 and R3. CPE3 is defined as the Warburg resistance with the factor, $n=0.5$ (Table $\mathrm{S} 2 \dagger$ ) and correspondingly, CPE1 becomes a pure capacitor with $n=1$. The Warburg resistance results from the solid-state ion diffusion in the electrode channels. The presence of $R 3$ points to the 


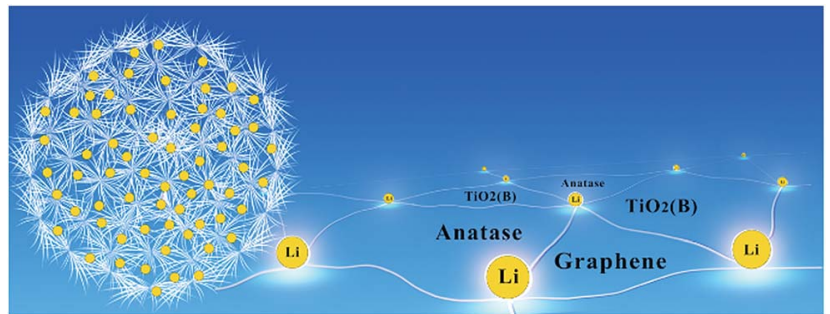

Fig. 6 Schematic representation of interfacial storage for $\mathrm{Li}^{+}$ions of $\mathrm{TiO}_{2} / M L G$

development of a surface resistance during cycling, which can be attributed to the open interfacial structure in the electrode or SEI film on the electrode surface. ${ }^{4}$ According to Tables S1 and $\mathrm{S} 2, \uparrow$ the resistances, $R 1$ and $R 2$ have decreased but the capacitance of CPE1 and CPE2 have increased after multiple electrochemical cycles when compared with those of the fresh cell. The impedance data indicate that the structural rearrangement of the $\mathrm{TiO}_{2} /$ MLG electrode during cycling promotes the boundary storage to be predominant over bulk storage for $\mathrm{Li}^{+}$ions. The interfacial structure provides more open channels for ion diffusion with cycling.

Fig. 6 is a schematic representation of the $\mathrm{TiO}_{2} / \mathrm{MLG}$ composite. The as-prepared material has an abundance of triphase boundaries between anatase $\mathrm{TiO}_{2}, \mathrm{TiO}_{2}(\mathrm{~B})$ and graphene. Wang et $a .^{42}$ have demonstrated that charge storage at the anatase $\mathrm{TiO}_{2}-\mathrm{TiO}_{2}(\mathrm{~B})$ junction can enhance $\mathrm{Li}^{+}$storage in anode materials. The high specific capacities observed for the biphasic $\mathrm{TiO}_{2}$ material prepared in the absence of MLG points to a synergistic interfacial effect improving charge storage. The specific capacitance of the dandelion structured $\mathrm{TiO}_{2}$ is further enhanced when MLG is introduced into the composite. The interfaces within nanosized materials can offer more sites for $\mathrm{Li}^{+}$storage ${ }^{36}$ and the boundaries between MLG and $\mathrm{TiO}_{2}$ phases also provide sites for Li storage. The MLG itself with nearly 30 layers will only contribute negligible capacity in the voltage range of 1-3 Vvs. $\mathrm{Li} / \mathrm{Li}^{+}{ }^{59}$ There are abundant phase boundaries arising from the polycrystal in the $\mathrm{TiO}_{2} / \mathrm{MLG}$ dandelion structure, contributing to large extent of lattice mismatch, as well as extra sites for $\mathrm{Li}^{+}$ion and electron storage and some disordered planes probably provide more active sites for $\mathrm{Li}^{+}$ion storage and transfer. ${ }^{\mathbf{4} 11}$ The $\mathrm{TiO}_{2} / \mathrm{MLG}$ composite is able to store charge through both $\mathrm{Li}^{+}$insertion and a pseudocapacitive mechanism, as evidenced by the $i-V$ curves obtained when the potential is cycled. We postulate that the improved rate performance of the $\mathrm{TiO}_{2} /$ MLG composite relative to the $\mathrm{TiO}_{2}$ material results from the fact that the edge-abundant interfaces of graphene can promote $\mathrm{Li}^{+}$ion diffusion and electron transport along the triphase boundaries, as schematically presented in Fig. 6.

\section{Conclusions}

Dandelion-shaped $\mathrm{TiO}_{2} /$ MLG composed of $\mathrm{TiO}_{2}(\mathrm{~B})$ fibrils and anatase pappi was synthesized as a promising anode material for $\mathrm{Li}$ storage. Both the material characterization and cyclic voltammetry presenting diffusion- and surface-controlled electrochemical reaction at different potentials, evidenced the anatase $/ \mathrm{TiO}_{2}(\mathrm{~B})$ heterophase in $\mathrm{TiO}_{2} / \mathrm{MLG}$, and the open channel saturation of $\mathrm{TiO}_{2}(\mathrm{~B})$ by inserted $\mathrm{Li}^{+}$ions at around $1.4 \mathrm{~V}$ was used to explain the irreversible cathodic peak. A mismatch rate, $\delta$, between two adjacent phases with mingled boundaries, was introduced to describe the interplanar mismatch degree. The edge-abundant interfaces of graphene involved in the triphase boundaries were reported to enhance the electrochemical storage properties of $\mathrm{TiO}_{2} / \mathrm{MLG}$ and lower the electrode polarization by the improvement of $\mathrm{Li}^{+}$diffusion and electron transport. The discharge capacities of $\mathrm{TiO}_{2} / \mathrm{MLG}$ at current densities of 0.05, 0.1, 0.2, 0.5, 1, 2, 3 and $5 \mathrm{~A} \mathrm{~g}^{-1}$ are 266, $243,221,200,182,161,140$ and $115 \mathrm{~mA} \mathrm{~h} \mathrm{~g}^{-1}$, and the capacity retention is $99.6 \%$ with high coulombic efficiency almost approaching $100 \%$ after 100 cycles at the current density of $0.1 \mathrm{~A}$ $\mathrm{g}^{-1}$. The resistances of $\mathrm{TiO}_{2} /$ MLG decreased with cycling and more boundaries were opened to enhance ionic and electron conductivity.

\section{Acknowledgements}

Financial support from the Imperial College PhD Scholarship, Engineering and Physical Sciences Research Council (EPSRC, Grant: EP/L015277/1) is greatly appreciated.

\section{Notes and references}

1 Y. Tang, Y. Zhang, W. Li, B. Ma and X. Chen, Chem. Soc. Rev., 2015, 5926-5940.

2 B. Kang and G. Ceder, Nat. Mater., 2009, 458, 190-193.

3 L. Kavan, J. Solid State Electrochem., 2014, 18, 2297-2306.

4 Q. Wu, J. Xu, X. Yang, F. Lu, S. He, J. Yang, H. J. Fan and M. Wu, Adv. Energy Mater., 2015, 5, 1401756-1401765.

5 J. Chen, W. Song, H. Hou, Y. Zhang, M. Jing, X. Jia and X. Ji, Adv. Funct. Mater., 2015, 25, 6793-6801.

6 S. Goriparti, E. Miele, M. Prato, A. Scarpellini, S. Marras, S. Monaco, A. Toma, G. C. Messina, A. Alabastri, F. D. Angelis, L. Manna, C. Capiglia and R. P. Zaccaria, ACS Appl. Mater. Interfaces, 2015, 7, 25139-25146.

7 B. Laskova, M. Zukalova, A. Zukal, M. Bousa and L. Kavan, J. Power Sources, 2014, 246, 103-109.

8 H. Ren, R. Yu, J. Wang, Q. Jin, M. Yang, D. Mao, D. Kisailus, H. Zhao and D. Wang, Nano Lett., 2014, 14, 6679-6684.

9 C. Kim, R. Buonsanti, R. Yaylian, D. J. Milliron and J. Cabana, Adv. Energy Mater., 2013, 3, 1286-1291.

10 M. Zhao, L. Li, H. Lin, L. Yang and G. Li, Chem. Commun., 2013, 49, 7046-7048.

11 Y. Ren, Z. Liu, F. Pourpoint, A. R. Armstrong, C. P. Grey and P. G. Bruce, Angew. Chem., Int. Ed., 2012, 51, 2164-2167.

12 J. Akimoto, Y. Gotoh, Y. Oosawa, N. Nonose, T. Kumagai, K. Aoki and H. Takei, J. Solid State Chem., 1994, 113, 27-36.

13 M. Latroche, L. Brohan, R. Marchand and M. Tournoux, J. Solid State Chem., 1989, 81, 78-82.

14 K. Spektor, D. T. Tran, K. Leinenweber and U. Häussermann, J. Solid State Chem., 2013, 206, 209-216. 
15 H. Sato, S. Endo, M. Sugiyama, T. kikegawa, O. Shimomura and K. Kusaba, Science, 1991, 251, 786-788.

16 Y. Al-Khatatbeh, K. K. M. Lee and B. Kiefer, Phys. Rev. B: Condens. Matter Mater. Phys., 2009, 79, 134114.

17 M. Mattesini, J. S. de Almeida, L. Dubrovinsky, N. Dubrovinskaia, B. Johansson and R. Ahuja, Phys. Rev. B: Condens. Matter Mater. Phys., 2004, 70, 212101.

18 N. A. Dubrovinskaia, L. S. Dubrovinsky, R. Ahuja, V. B. Prokopenko, V. Dmitriev, H. P. Weber, J. M. OsorioGuillen and B. Johansson, Phys. Rev. Lett., 2001, 87, 275501.

19 L. S. Dubrovinsky, N. A. Dubrovinskaia, V. Swamy, J. Muscat, N. M. Harrison, R. Ahuja, B. Holm and B. Johansson, Nature, 2001, 410, 653-654.

20 D. O. Scanlon, C. W. Dunnill, J. Buckeridge, S. A. Shevlin, A. J. Logsdail, S. M. Woodley, C. R. A. Catlow, M. J. Powell, R. G. Palgrave, I. P. Parkin, G. W. Watson, T. W. Keal, P. Sherwood, A. Walsh and A. A. Sokol, Nat. Mater., 2013, 12, 798-801.

21 D. D'Elia, École Nationale Supérieure des Mines de Paris, 2011.

22 S. Moitzheim, C. S. Nimisha, S. Deng, D. J. Cott, C. Detavernier and P. M. Vereecken, Nanotechnology, 2014, 25, 504008 .

23 T. Zhou, Y. Zheng, H. Gao, S. Min, S. Li, H. K. Liu and Z. Guo, Adv. Sci., 2015, 2, 1500027.

24 S. Li, M. Ling, J. Qiu, J. Han and S. Zhang, J. Mater. Chem. A, 2015, 3, 9700-9706.

25 X. Yan, Y. Li, M. Li, Y. Jin, F. Du, G. Chen and Y. Wei, J. Mater. Chem. A, 2015, 3, 4180-4187.

26 K. Siuzdak, R. Bogdanowicz, M. Sawczak and M. Sobaszek, Nanoscale, 2015, 7, 551-558.

27 X. Yang, Y. Yang, H. Hou, Y. Zhang, L. Fang, J. Chen and X. Ji, J. Phys. Chem. C, 2015, 119, 3923-3930.

28 Z. Hong, M. Wei, T. Lan, L. Jiang and G. Cao, Energy Environ. Sci., 2012, 5, 5408-5413.

29 G. Li, Z. Lian, X. Li, Y. Xu, W. Wang, D. Zhang, F. Tian and H. Li, J. Mater. Chem. A, 2015, 3, 3748-3756.

30 H. Tian, F. Xin, X. Tan and W. Han, J. Mater. Chem. A, 2014, 2, 10599-10606.

31 S. Wei, R. Wu, J. Jian, F. Chen and Y. Sun, Dalton Trans., 2015, 44, 1534-1538.

32 W. Jiao, N. Li, L. Wang, L. Wen, F. Li, G. Liu and H.-M. Cheng, Chem. Commun., 2013, 49, 3461-3463.

33 W. Zhang, Y. Gong, N. P. Mellott, D. Liu and J. Li, J. Power Sources, 2015, 276, 39-45.

34 Z. Ali, S. N. Cha, J. I. Sohn, I. Shakir, C. Yan, J. M. Kim and D. J. Kang, J. Mater. Chem., 2012, 22, 17625-17629.
35 M. Lübke, I. Johnson, N. M. Makwana, D. Brett, P. Shearing, Z. Liu and J. A. Darr, J. Power Sources, 2015, 294, 94-102.

36 J.-Y. Shin, D. Samuelis and J. Maier, Adv. Funct. Mater., 2011, 21, 3464-3472.

37 J. Maier, Nat. Mater., 2005, 4, 805-815.

38 J. Jamnik and J. Maier, Phys. Chem. Chem. Phys., 2003, 5, 5215-5220.

39 Y. F. Zhukovskii, P. Balaya, E. A. Kotomin and J. Maier, Phys. Rev. Lett., 2006, 96, 058302.

40 D. Yang, H. Liu, Z. Zheng, Y. Yuan, J.-c. Zhao, E. R. Waclawik, X. Ke and H. Zhu, J. Am. Chem. Soc., 2009, 131, 17885-17893. 41 N. Fu, Y. Wu, Z. Jin and G. Lu, Langmuir, 2010, 26, 447-455. 42 R. Wang, X. Xue, W. Lu, H. Liu, C. Lai, K. Xi, Y. Che, J. Liu, S. Guo and D. Yang, Nanoscale, 2015, 7, 12833-12838.

43 W. Song, X. Cao, Z. Wu, J. Chen, Y. Zhu, H. Hou, Q. Lan and X. Ji, Langmuir, 2014, 30, 12438-12446.

44 W. Song, X. Ji, Z. Wu, Y. Zhu, Y. Yang, J. Chen, M. Jing, F. Li and C. E. Banks, J. Mater. Chem. A, 2014, 2, 5358-5362.

45 G. Armstrong, A. R. Armstrong, J. Canales and P. G. Bruce, Chem. Commun., 2005, 2454-2456.

46 T. P. Feist and P. K. Davies, J. Solid State Chem., 1992, 101, 275-295.

47 N. Li, G. Liu, C. Zhen, F. Li, L. Zhang and H.-M. Cheng, Adv. Funct. Mater., 2011, 21, 1717-1722.

48 X. Huang, K. Wang, K. Jia and X. Liu, Polym. Adv. Technol., 2015, 26, 1267-1274.

49 H. Sun, S. Liu, S. Liu and S. Wang, Appl. Catal., B, 2014, 146, 162-168.

50 J. S. Chen, Z. Wang, X. C. Dong, P. Chen and X. W. Lou, Nanoscale, 2011, 3, 2158-2161.

51 L. Wang, L. Shen, Y. Li, L. Zhu, J. Shen and L. Wang, Int. J. Photoenergy, 2013, 2013, 1-7.

52 Q. Huang, S. Tian, D. Zeng, X. Wang, W. Song, Y. Li, W. Xiao and C. Xie, ACS Catal., 2013, 3, 1477-1485.

53 Y. Gao, X. Pu, D. Zhang, G. Ding, X. Shao and J. Ma, Carbon, 2012, 50, 4093-4101.

54 M. Hu, M. Fang, C. Tang, T. Yang, Z. Huang, Y. Liu, X. Wu and X. Min, Nanoscale Res. Lett., 2013, 8, 548.

55 D. A. H. Hanaor and C. C. Sorrell, J. Mater. Sci., 2010, 46, 855874.

56 M. Zukalová, M. Kalbáč, L. Kavan, I. Exnar and M. Graetzel, Chem. Mater., 2005, 17, 1248-1255.

57 Y.-G. Guo, Y.-S. Hu and J. Maier, Chem. Commun., 2006, 2783. 58 Y. S. Hu, L. Kienle, Y. G. Guo and J. Maier, Adv. Mater., 2006, 18, 1421-1426.

59 E. Yoo, J. Kim, E. Hosono, H.-s. Zhou, T. Kudo and I. Honma, Nano Lett., 2008, 8, 2277-2282. 